\title{
Schumpeterian Growth and Endogenous Business Cycles
}

\author{
Kerk L. Phillips* \\ Department of Economics \\ P.O. Box 22363 \\ Brigham Young University \\ Provo, UT 84602-2363 \\ phone: (801) 378-5928 \\ fax: (801) 378-2844 \\ email: kerk_phillips@byu.edu
}

\author{
Jeff Wrase* \\ Research Department \\ Federal Reserve Bank of Philadelphia \\ Ten Independence Mall \\ Philadelphia, PA 19106-1574 \\ phone: (215) 574-3985 \\ fax: (215) 574-4364 \\ email: jeffrey.wrase@phil.frb.org
}

* We wish to thank Val Lambson and the participants of the 1999 Theories and Methods in Macroeconomics Conference held at the University of Quebec at Montreal for helpful comments. Funding for travel and presentation of this research from the Federal Reserve Bank of Philadelphia and from the J. Fish Smith Endowed Chair in Free Markets is gratefully acknowledged. The views expressed in this paper are not necessarily those of the Federal Reserve Bank of Philadelphia, Brigham Young University, or the Federal Reserve System. 


\section{JEL Codes: E32, O30, O40}

\section{Introduction}

Dynamic general equilibrium models have proved to be valuable tools for examining both economic growth and fluctuations. One class of these models, the Schumpeterian or "quality ladders" models, focuses on explaining observed smooth growth trends. Segerstrom, Anant and Dinopoulos (1990), Grossman and Helpman (1991) and Aghion and Howitt (1992) first introduced this literature in seminal papers. In addition, there have been numerous extensions of the basic quality ladders model, focusing on innovation versus imitation, North-South trade patterns, and other related topics. ${ }^{1}$

The Shumpeterian models have the advantage that they are rigorously derived while having a great deal of intuitive appeal. In this literature, growth is driven endogenously by attempts to innovate and climb up the quality ladder to capture a stream of monopoly profits. Attention is normally focused on the steady state, where growth is smooth over time due to a large number of independent, but identical industries. Growth in any given industry, however, proceeds in a lumpy fashion with discrete jumps in quality occurring randomly over time.

A second class of models focuses on explaining the behavior of economic aggregates over the course of the business cycle. Originally referred to as real business cycle (RBC) models, early work began with seminal papers by Kydland and Prescott (1982) and Long and Plosser (1983). Again, numerous papers have extended this literature to the examination of aggregate labor behavior, monopolistic competition, monetary aggregates, and various other areas of inquiry. ${ }^{2}$

The RBC literature generally involves building a general equilibrium model, with changes in productivity (and, perhaps, other economic fundamentals) driving aggregate behavior, capable of

${ }^{1}$ For an extensive overview of this literature see Grossman and Helpman (1991) and Aghion and Howitt (1998).

${ }^{2}$ For an excellent overview of the RBC literature see Cooley (1995). 
generating artificial data that mimic observed business cycles. Unlike the Schumpeterian literature, attention is focused on the off-steady-state, high-frequency, behavior of aggregate economic variables.

In practice, $\mathrm{RBC}$ models are typically transformed into a stationary variant and solved numerically to yield stationary laws of motion for endogenous variables as functions of endogenous states and exogenous driving processes. A stationary model economy is then simulated and evaluated by comparing properties of data drawn from the model with data drawn from actual economies. Since the focus of RBC models is on high-frequency fluctuations and not on economic growth, the growth component is usually ignored. However, in order to compare the artificial economy with real world data it is necessary to detrend the real world data. While many business cycle stylized facts are invariant to the filter used, there are some important facts that are not ${ }^{3}$.

Generally in RBC models, the source of shocks is an exogenously imposed sequence of large and volatile productivity shocks. A common specification of such shocks is a simple AR(1), and there is little or no economic theory involved in the specification of the driving process. Moreover, there is increasing skepticism that technology shocks, measured by Solow residuals, are a major source of business cycle fluctuations. As King and Rebelo (1998) point out "A key difficulty is that typical estimates of Solow residuals imply a probability of technical regress on the order of $40 \%$, which seems implausible to most economists."

This paper integrates the two branches of literature identified above: the RBC literature, which focuses on detrended, high frequency fluctuations; and the Shumpeterian literature, which focuses on low-frequency growth trends. The objective is to construct a dynamic general equilibrium model with an endogenous driving process for business cycles derived from microeconomic primitives, and with high- and low-frequency movements in economic aggregates that mimic those observed in the U.S. economy. The endogenous growth component of the model is included in simulations, which create artificial data. Properties of the artificial data are then compared to like

\footnotetext{
${ }^{3}$ See Canova (1998).
} 
properties of their real data counterparts to evaluate the model's performance. ${ }^{4}$ An important feature of the model is that growth and cyclical properties of data stem from a common sourceendogenous innovations to technology. Technical regress is not necessary for business cycle fluctuations in the model. Rather, the endogenous movements of resources between goods production and technological advancement gives rise to cyclical fluctuations, as well as lower frequency movements in key macroeconomic variables. In principle, the model does not require large and variable technology shocks that imply high likelihoods of technical regress to explain business cycles. Rather, endogenous improvements in technology and the diffusion of the improvements into production of final goods can help explain both growth and cycles.

\section{Methodology}

Our methodology is as follows. We incorporate features of the Schumpeterian growth literature into a real business cycle model of the macroeconomy. We interpret what are usually called increases in quality in the Shumpetarian literature as increases in productivity, and we keep the quality of goods constant over time. A small number of industries are assumed, which gives rise to aggregate growth in technology that is "lumpy" and can therefore serve as a driving process for business cycles. The model is evaluated by: linearizing agents' Euler equations, with market clearing conditions imposed; numerically solving the model for endogenous variables as functions of endogenous states and exogenous shocks; simulating the model to generate sequences of macroeconomic aggregates; comparing properties of data generated by the model with properties of data drawn from the U.S. economy at both high- and low- frequencies.

There are three sources of shocks in the model. One is a sequence of random draws to determine success or failure of potential innovators who invest resources in basic research and development (R\&D) to influence their success probabilities. A second source is a random draw,

4 Note that since growth is endogenous in the model, the choice of which particular detrending method to use is less critical than in a protoypical RBC model. 
which partly determines the rate of diffusion of basic into applied R\&D. The final source of shocks is innovations to labor productivity governed by a process typically used in RBC models.

We find that in the dynamic Shumpetarian model with only RBC-style shocks to technology, data drawn from model simulations do not possess business cycle-frequency fluctuations in macroeconomic aggregates found in actual U.S. data. Furthermore, in the model with only shocks to basic R\&D, the model also fails to produce data with properties in line with observations because innovations occur too infrequently and are large. Infrequent and large innovations to basic R\&D produce data that have far too many low-frequency spikes in aggregates. However, when all three shocks are combined, the model produces data with properties that are in line with observations.

The model with endogenous R\&D innovations can account for key properties of actual data without heavy reliance on exogenous, highly persistent and volatile RBC-style shocks to productivity. In addition, RBC-style productivity shocks alone will not produce business cycle dynamics in the model that resemble those found in actual data. We also require innovations to basic R\&D and, to eliminate the low-frequency spike effects on macroeconomic aggregates of basic R\&D innovations alone, shocks to applied R\&D which serve to smooth out, or diffuse, the spike effects of basic R\&D.

\section{A Comparison with Other Dynamic Shumpetarian Models}

Our approach is related to recent work by Andolfatto and MacDonald (1998), Collard (1999), Freeman, Hong, and Peled (1999), and Ozlu (1996) which also focuses on dynamic implications of endogenous growth models.

Collard and Ozlu each consider extensions of a standard RBC model to include endogenous growth through human capital accumulation effects of learning-by-doing. Ozlu considers labor market implications of allowing learning-by-doing effects on human capital, while Collard considers implications for the autocorrelation of output growth and impulse response functions in the trendreverting component in output. These authors find improvements in quantitative implications of RBC models augmented to include learning-by-doing effects over standard RBC models without human capital features. Our analysis is similar to those performed by Collard and Ozlu in two 
respects. First, we also consider business cycle implications of an RBC model augmented to include an endogenous growth mechanism. Second, as in Collard's analysis, we consider implications of our model for fluctuations in key variables at various frequencies including, but not limited to, business cylce frequencies. Our model differs from the other authors, however, in an important way. While Collard and Ozlu essentially provide a model of an endogenous mechanism for the propagation of exogenous technology shocks, we model both propagation of shocks and the shocks themselves. That is, we present a model that accounts for how shocks to technology arise, as well as how they may be propagated and diffused through time.

Closer to the spirit of our analysis is the work by Andolfatto and MacDonald, and by Freeman, Hong, and Peled. The latter set of authors construct a model of large and costly technological changes which give rise to deterministic cycles and long run growth. Their economy requires a sufficiently large amount of capital, diverted from consumption and physical investment, for birth of a technological innovation. Then, when an innovation occurs, capital is more highly valued in physical investment than in R\&D investment. Consequently, resources flow away from $R \& D$ and toward final goods production. As the marginal product of capital using existing technology fades through time, resources subsequently flow back toward consumption and the production of $R \& D$ innovations. These flows of capital give rise to endogenous movements in consumption and investment patterns within each fixed-length innovation cycle. Our analysis similarly accounts for endogenous movements in key macroeconomic variables within innovation cycles, but also explicitly models innovation cycles of random durations. ${ }^{5}$ In addition, when exploring quantitative predictions of our model relative to quantitative properties of actual data, we explicitly consider movements in key macroeconomic variables at well-defined frequencies. In

5 Another difference between our model and the one constructed by Freeman, Hong, and Peled is that our model considers labor, rather than capital, as the input to the R\&D process. We include only labor to simplify the analysis, but are free to enter capital into the R\&D process as well. 
contrast, Freeman, Hong, and Peled are agnostic about the frequency one should look at in actual data for the innovation-driven cyclical patterns of movements that their model predicts.

The analysis of Andolfatto and MacDonald is close to that in this paper in that they consider fluctuations and growth in key macroeconomic aggregates arising from the discovery and diffusion of technological innovations. As in our model, Andolfatto and MacDonald have growth arising from technological discovery and use, and fluctuations arising from diffusion of applied, or frontier, research. Some type of diffusion mechanism is required in each model to smooth out what would otherwise be unrealistic spikes in economic aggregates from infrequent, possibly large, technological innovations springing up from applied research.

Andolfatto and MacDonald consider a diffusion mechanism involving imitation and learning how to use new technology, which divert resources from production. Agents choose the amount of resources to devote to various imitation and learning possibilities available to them, the outcomes of which are random. With such a mechanism, the authors compare Hodrick-Prescott filtered series (in levels, not deviations from filtered series) from actual data with like series drawn from their model.

Our model has a slightly different mechanism for innovation and diffusion than that in Andolfatto and MacDonald. In our model, innovations in applied research are diffused into basic know-how through a random process that is linked to the amount of resources diverted from goods production to applied R\&D. Our model shares with Andolfatto and MacDonald's model the important feature that there is a link between resources used in R\&D production and the ease by which innovations diffuse into basic knowledge. While the mechanics of the diffusion specifications differ slightly across models, in both cases growth and fluctuations are merely different features of the processes of technological discovery and diffusion. We also share with Andolfatto and MacDonald's model randomness in the ease of diffusing applied research into basic know-how.

Our analysis differs from Andolfatto and MacDonald's in the frequencies of movements in macroeconomic variables considered. Our model is an attempt at simultaneously accounting for growth and business cycle fluctuations. Consequently, we consider movements in macroeconomic variables at various frequencies, including those that arise at business cycle frequencies. We do not 
restrict attention to data movements at frequencies at or below those at which major innovations diffuse, as do Andolfatto and MacDonald.

\section{A Dynamic General Equilibrium Shumpetarian Model}

In this section, insights of the Schumpeterian or "quality ladders" growth models are incorporated into a discrete-time stochastic general equilibrium model of the real business cycle tradition. Since it is well known that the equilibrium from Schumpeterian growth models is socially suboptimal, we proceed to examine the competitive equilibrium. First, we examine the behavior of households, then that of production firms, and finally the behavior of research firms. Imposing aggregate resource constraints and market clearing conditions closes the model. ${ }^{6}$

The model contains households, production firms, and research firms. Each infinitely lived household is endowed with one unit of labor each period supplied to firms at wage $w$. Households also accumulate physical capital, $K$, over time, which they rent to firms each period at rental rate $r_{t}$. In addition to physical capital, households buy and sell equity shares in two types of existing firms-production and research firms--in $I$ different intermediate industries. These shares influence the household's budget by generating dividends and capital gains or losses. There is also a final goods sector, which we assume is perfectly competitive and generates no profits. For simplicity, we abstract from buying and selling of these firms' equities?

In each period there is a single production firm in each intermediate industry with an exclusive right to a particular level of production technology, $A_{i}$, that is some factor $\theta>1$ better than the closest competitor. This production firm enjoys monopoly power and earns monopoly rents during the current period, and possibly many future periods, until a firm with even better technology replaces it. The production firms hire labor and rent capital to produce intermediate goods, and pay

${ }^{6} \mathrm{~A}$ listing of notation and variables used in the model is contained in Table 1.

7 The assumption is innocuous because these equities would have zero prices. 
out profits as dividends to shareholders each period. Final goods are produced by combining intermediate goods.

There also exists a single new research firm for each intermediate industry, which incorporates with the intent of displacing the current production firm in its role of monopolist. The research firm issues equity shares and uses the proceeds to hire units of labor to attempt an innovation. If successful, the research firm discovers a technology that is a factor $\theta$ better than the current production firm and begins production as the monopolist next period. If unsuccessful, the firm ceases to exist and its equity shares become worthless. We account for successes and failures across the i industries with an i-dimensional vector $\mathbf{S}^{\prime}$, with element $S_{i}^{\prime}=1$ if a research firm succeeds in the current period and $S_{i}^{\prime}=0$ if not. If $S_{i}^{\prime}=1$, then today's research firm in industry $i$ becomes the production firm tomorrow with technology $A_{i}^{\prime}$ that is a factor $\theta$ better than it's predecessor. ${ }^{8}$

Preliminary quantitative investigations of the model with only shocks to a random process determining whether research firms are successful or not revealed that fluctuations in output would be too much like a step-function to resemble business cycles. Consequently, to allow for more gradual implementation of technological discoveries, which serves to smooth out effects on variables of the step-like applied, or "frontier," research innovations, we include two stocks of knowledge in the model presented below-i.e. two R\&D processes.

One set of knowledge stocks, denoted $A_{i}$ in industry $i=1,2, \mathrm{I}$, are the applied R\&D stocks used in production of intermediate goods. The second, denoted $B_{i}$ for basic knowledge, represent knowhow that derives, or diffuses, from frontier innovations gradually over time. Basic knowledge enters the model in that a higher value of the ratio of basic to applied knowledge in an industry,

8 We adopt the notation convention that variables without a prime denote current period values and variables with a prime denote next-period values. Additionally, bold letters are used to denote i-dimensional vectors of variables. 
$b_{i} \equiv B_{i} / A_{i}$, raises the likelihood of success in applied R\&D innovations $A_{i}$. For example, the larger the base of knowledge about digital computing in a computer-related industry, the higher the likelihood of a successful R\&D outcome that pushes the knowledge frontier in that industry.

The evolution of the $B_{i}$ 's over time is modeled as being a byproduct of the production of applied technology. Innovations in basic knowledge are specified as a function of the amount of applied R\&D taking place. As the amount of applied R\&D taking place increases, the likelihoods of basic R\&D successes increase. However, we do not want to limit the stock of basic R\&D in an industry to two possible outcomes-success or failure. Rather, by modeling the basic R\&D knowledge stock in an industry as a continuous random variable, the model allows for a continuum of possible realizations for each industry's basic stock of knowledge. We discuss the basic R\&D process in greater detail below.

There is also an aggregate random shock to productivity in the model, unrelated to any of the $A_{i}$ 's or $B_{i}$ 's which we denoted by $z$. These exogenous shocks are to the productivity of labor in the intermediate goods producing firms' production functions. We include such shocks to allow for shocks to productivity unrelated to actual movements in technology, such as oil price shocks, changes in marginal tax rates, changes in government regulation of production processes, or other such shocks. This shock to productivity, assumed to be common to all $I$ intermediate good producers, is of the form used in standard RBC models. One of our interests will be the extent to which, by allowing for random innovations in $\mathrm{R} \& \mathrm{D}$, the model does not require productivity shocks that are as persistent and volatile as those typically employed in RBC models to explain business cycle fluctuations.

The timing of information, shocks, and activities in the economy is as follows. Agents begin a period with capital stock $\mathrm{K}$ knowing research and shock realizations $\mathbf{B}, \mathbf{A}$, and $z$. At the beginning of the period, factor and equity markets open and clear. Firms rent capital from households, and rental rate $r$ is determined. Firms also hire labor from households, and real wage $w$ is determined. Research firms issue shares, and prices of those shares, $\mathbf{q}^{R}$, are determined, and production firms 
issue shares, and their prices, $\mathbf{q}^{P}$, are determined. Following input and funding acquisitions, production of goods and research occurs and the research results and random shocks $\mathbf{B}^{\prime}, \mathbf{A}^{\prime}$, and $z^{\prime}$ are revealed. Subsequently, at the end of the period, factor payments $w$ and $r K$ are made, production-firm profits $\pi$ are distributed to shareholders, next period's capital stock $K$ ' is chosen, and consumption occurs. We now turn to decisions made by the household, production firms, and research firms.

\section{The Household's Problem}

A representative household enters a period with capital $K$ carried over from the previous period and a normalized unit time endowment. 9 The household also owns stocks of equity shares in last period's production and research firms, denoted by share vectors $\mathbf{P}$ and $\mathbf{R}$. The household knows the current levels of technology, A, to be employed by this period's production firms, the current random productivity shock, $z$, and whether last period's research firms succeeded or failed, the vector S. Taking prices $r, w, \mathbf{q}^{P}, \mathbf{q}^{R}$, and the probabilities of success by the current research firms, $\rho$, as given, the household chooses new stocks of equities $\mathbf{P}^{\prime}$ and $\mathbf{R}^{\prime}$ to carry over to next period.

After production is completed and next period's values for technology, $\mathbf{B}^{\prime}, \mathbf{A}^{\prime}$, and $z^{\prime}$, are revealed, the household chooses a level of capital, $K$, to carry into next period. Consumption then occurs according to the household's choices and budget constraint.

The value function for the household is:

$$
V(K, \mathbf{P}, \mathbf{R} ; \mathbf{O})=\underset{P^{\prime}, R^{\prime}}{\operatorname{ax}} E\left\{\underset{K^{\prime}}{\operatorname{Max}} u(C)+\beta V\left(K^{\prime}, \mathbf{P}^{\prime}, \mathbf{R}^{\prime} ; \mathbf{O}^{\prime}\right)\right\}
$$

where: $\quad C=w+(1-\delta+r) K-K^{\prime}+\sum_{i=1}^{I}\left[\pi_{i}+q_{i}{ }^{P}\right]\left[\left(1-S_{i}\right) P_{i}+S_{i} R_{i}\right]-q_{i}{ }^{P} P_{i}^{\prime}-q_{i}{ }^{R} R_{i}{ }^{\prime}, \quad u(\mathrm{C}) \quad$ is $\quad$ the momentary utility function, $\beta$ is the discount factor, $\mathbf{O}=\left\{w, r, \mathbf{q}^{R}, \mathbf{q}^{P}, \mathbf{S}, \mathbf{?}\right\}$ is an information set,

9 The household supplies it's normalized unit time endowment inelastically, and therefore receives wages $w^{*} 1$. The unit time endowment is divided between research and production firms' activities. 
and $\mathrm{E}$ is the expectation operator given information available at the beginning of the period. $\rho$ in the information set represents the vector of industry R\&D success probabilities. S represents the vector of industry R\&D success indicator variables, taking values of 1 if a success occurs, and 0 if failure occurs.

For industry i, $\rho_{i}$ is the probability of an applied research firm successfully innovating in the current period to become next period's intermediate goods producer with an improved technology. We explicitly model the innovation probabilities below in the discussion of the research firms' problems. What is relevant for the household's decision is that with probability $\rho_{i}$ a share in today's industry $i$ research firm will pay off next period. If today's research firm pays off next period, then a share in that industry's current intermediate goods producing firm will not pay off next period because it is replaced by the current period's successful innovator. Correspondingly, with probability $1-\rho_{i}$, industry $i$ 's current research firm is unsuccessful and won't pay off next period. Then, the current intermediate goods producer remains as next period's producer providing payoffs on its shares.

The envelope conditions from the household's problem consist of I conditions each for the shares $P_{i}$ and $R_{i}$, and a condition for capital stock $K$ given, respectively, by:

$$
\begin{aligned}
& V_{P}^{i}(K, \mathbf{P}, \mathbf{R} ; \mathbf{O})=E\left\{u_{C}(C)\right\}\left(\pi_{i}+q_{i}^{P}\right)\left(1-S_{i}\right) \text { for } \mathrm{i}=1,2, \mathrm{I} . \\
& V_{R}^{i}(K, \mathbf{P}, \mathbf{R} ; \mathbf{O})=E\left\{u_{C}(C)\right\}\left(\pi_{i}+q_{i}^{P}\right) S_{i} \text { for } \mathrm{i}=1,2, \mathrm{I} . \\
& V_{K}(K, \mathbf{P}, \mathbf{R} ; \mathbf{O})=E\left\{u_{C}(C)\right\}(1-\delta+r)
\end{aligned}
$$

The Euler equations corresponding to the household's choices consist of I conditions each for next period shares $P_{i}^{\prime}$ and $R_{i}^{\prime}$, and a condition for next period's capital stock $K^{\prime}$ given by:

$$
\begin{aligned}
& E\left\{u_{C}(C)\right\}\left(-q_{i}^{P}\right)+\beta E\left\{V_{P}^{i}\left(K^{\prime}, \mathbf{P}^{\prime}, \mathbf{R}^{\prime} ; \mathbf{O}^{\prime}\right)\right\}=0 \text { for } \mathrm{i}=1,2, \ldots, \mathrm{I} . \\
& E\left\{u_{C}(C)\right\}\left(-q_{i}^{R}\right)+\beta E\left\{V_{R}^{i}\left(K^{\prime}, \mathbf{P}^{\prime}, \mathbf{R}^{\prime} ; \mathbf{O}\right)\right\}=0 \text { for } \mathrm{i}=1,2, \ldots, \mathrm{I} . \\
& u_{C}(C)(-1)+\beta V_{K}^{i}\left(K^{\prime}, \mathbf{P}^{\prime}, \mathbf{R}^{\prime} ; \mathbf{O}\right)=0
\end{aligned}
$$


Combining envelope and Euler equations gives the following $2 \mathrm{I}+1$ system of equations:

$$
\begin{aligned}
& E\left\{u_{C}(C)\right\} q_{i}^{P}=\beta\left(1-\rho_{i}\right) E\left\{u_{C}\left(C^{\prime}\right)\left(\pi_{i}{ }^{\prime}+q_{i}^{P^{\prime}}\right) \mid A_{i}=\theta\right\} \quad \text { for } \mathrm{i}=1,2, \mathrm{I} . \\
& E\left\{u_{C}(C)\right\} q_{i}^{R}=\beta \rho_{i} E\left\{u_{C}\left(C^{\prime}\right)\left(\pi_{i}^{\prime}+q_{i}^{P \prime}\right) \mid A_{i}=1\right\} \text { for } \mathrm{i}=1,2, \mathrm{I} . \\
& u_{C}(C)=\beta E\left\{u_{C}\left(C^{\prime}\right)\left(1-\delta+r^{\prime}\right) \mid B^{\prime}, \mathbf{A}^{\prime}, z^{\prime}\right\}
\end{aligned}
$$

where expectation operator $E\{\mathrm{x} \mid \mathrm{y}\}$ denotes the expectation of $\mathrm{x}$ given all the information available at the beginning of the period, plus additional information revealed after the beginning of the period that is contained in $\mathrm{y}$.

The laws of motion governing each industry's applied technology level $A_{i}$, applied research success index $S_{i}$, exogenous technology shock z, and basic technology level $B_{i}$, known to the household, are:

$$
\begin{aligned}
& A_{i}{ }^{\prime}, S_{i}{ }^{\prime}= \begin{cases}\theta A_{i}, 1 & \text { with probabilit y } \rho_{i} \\
A_{i}, 0 & \text { with probabilit y } 1-\rho_{i}\end{cases} \\
& z^{\prime}=\psi z+\eta^{\prime} ; \text { where } \eta^{\prime} \text { is distributed Normal }\left(0, \sigma^{2}\right) \\
& B_{i}{ }^{\prime}=\lambda^{H_{i}} B_{i} ; \text { where } \mathrm{H} \text { is distributed Poisson with parameter value } \phi_{i} .
\end{aligned}
$$

The endogenous choices and random shocks governing the applied R\&D success probabilities $\rho_{i}$ are discussed in detail below when the R\&D firms' choice problems are discussed. The $z$ shocks are the productivity shocks discussed earlier. The Poisson parameter in the evolution of the basic knowledge stocks in (2.6) is assumed to be proportional to the total employment in applied R\&D, and can be written as $\phi_{i}=f L_{i}$.

Modeling innovations to the stock of basic knowledge as a continuous function of employment in applied R\&D captures the idea that increased applied R\&D increases the likelihood of a basic R\&D success. This is the sense in which the model allows for diffusion of applied, "frontier," research into stocks of basic know-how in the economy. Since the innovation to the stock of basic knowledge in an industry is a continuous function of that industry's applied R\&D stock, we do not limit basic knowledge advances to mere success or fail outcomes. 


\section{Production of Final Goods}

Final goods production is an Armington aggregator of all intermediate goods, and uses no capital or labor. ${ }^{10}$

$$
Y=I \prod_{i=1}^{I} Y_{i}^{1 / I}
$$

Firms view the prices of intermediate goods as fixed, and a typical firm maximized profits:

$$
\Pi_{F}=I \prod_{i=1}^{I} Y_{i}^{1 / I}-\sum_{i=1}^{I} p_{i} Y_{i}
$$

First-order conditions for the firm's problem yield:

$$
p_{i} Y_{i}=\frac{Y}{I}
$$

showing that all intermediate firms earn the same amount of real revenue. Alternatively stated, regardless of the amount produced, expenditures on each intermediate good are equal.

\section{$\underline{\text { Production of Intermediate Goods }}$}

The production firm produces output using a Cobb-Douglas production function with two sources of productivity variation, both of which are assumed to be labor augmenting:

$$
Y_{i}=\left(K_{i}\right)^{\alpha}\left[\exp (z) \cdot A_{i} \cdot N_{i}\right]^{1-\alpha}
$$

Productivity variations come from productivity shocks, $z$, along with the endogenous growth shocks $A_{i}$

The monopolistic production firm faces a downward sloping demand curve defined by (2.9). However, there is a potential competitor that places limits on the price the monopolist will charge.

10 We could take the usual approach and use this aggregator as a utility function expressing a preference for variety across the $I$ intermediate goods. Interpreting it as a final good, however, has the advantage of yielding a natural numeraire good for the calculation of real values. 
The previous producer of the good has access to a technology that is $1 / \theta$ as productive as the current firm's. The current firm will never charge a price that exceeds its marginal cost by more than a factor of $\theta^{1-\alpha}$. To do so would be to surrender production to the previous producer. It can easily be shown that the marginal cost for the current firm is:

$$
\left(\frac{1}{e^{z} A_{i}}\right)^{1-\alpha}\left[\left(\frac{\alpha}{1-\alpha}\right)^{1-\alpha}+\left(\frac{1-\alpha}{\alpha}\right)^{\alpha}\right] w^{1-\alpha} r^{\alpha},
$$

while the marginal cost for its closest competitor is:

$$
\left(\frac{\theta}{e^{z} A_{i}}\right)^{1-\alpha}\left[\left(\frac{\alpha}{1-\alpha}\right)^{1-\alpha}+\left(\frac{1-\alpha}{\alpha}\right)^{\alpha}\right] w^{1-\alpha} r^{\alpha}
$$

Hence, the optimal price for the firm is to charge a multiplicative markup of $\theta^{1-\alpha}$ over marginal cost.

Standard optimality conditions for the firm reveal that is divides revenues between payments to labor, capital, and dividends according to:

$$
\begin{aligned}
& w N_{i}=\frac{1-\alpha}{\theta^{1-\alpha}} p_{i} Y_{i}=\frac{1-\alpha}{\theta^{1-\alpha} I} Y \\
& r K_{i}=\frac{\alpha}{\theta^{1-\alpha}} p_{i} Y_{i}=\frac{\alpha}{\theta^{1-\alpha} I} Y \\
& \pi_{i}=\frac{\theta^{1-\alpha}-1}{\theta^{1-\alpha}} p_{i} Y_{i}=\frac{\theta^{1-\alpha}-1}{\theta^{1-\alpha} I} Y
\end{aligned}
$$

These distribution equations show that capital, labor, and profits are identical for all intermediate firms regardless of the level of technology they use. The aggregate values are, then, $K=I K_{i}$, $N=I N_{i}$ and $\pi=I \pi_{i}$. Substituting these values into (2.9) and (2.6), the production of final goods can be written as an aggregate production function of the form:

$$
\begin{gathered}
Y=I \prod_{i=1}^{I}\left[K_{i}^{\alpha}\left(e^{z} A_{i} N_{i}\right)^{1-\alpha}\right]^{1 / I}=K^{\alpha}\left(e^{z} A N\right)^{1-\alpha} \\
\quad \text { where } A \equiv \prod_{i=1}^{I} A_{i}^{1 / I}
\end{gathered}
$$


So, we can collapse the production of intermediate and final goods into a single aggregate production function.

Given the manner in which the $A_{i}$ evolve in (2.4), and the aggregation in (2.12), aggregate technology, $A$, evolves according to the following Binomial law of motion:

$$
A^{\prime}=A \theta^{J / I} ; \text { with } J \text { distributed as } \operatorname{Binomial}(I, \rho)
$$

\section{The Research Firm's Problem}

Each period a single research firm springs into existence in each industry. It sells equity shares, normalized to a quantity of one, to the household at price $q_{i}^{R}$, and uses the proceeds to hire labor. Taking prices $w$ and $q^{R}$ as fixed, the firm chooses the amount of labor to hire by solving:

$$
\underset{L_{i}}{\operatorname{Max}} \Pi_{R}=\rho_{i} E\left\{\frac{V_{i}^{\prime}}{1+r} \mid S^{\prime}=1\right\} \text { s.t. } w L_{i} \leq q_{i}^{R}
$$

where $V_{i}^{\prime}=\pi_{i}{ }^{\prime}+q_{i}^{P}$ ' is the reward for a successful innovation, and $\rho_{\mathrm{l}}$ is the probability of success.

The reward for success consists of the expected present value of the stream of profits given that a success occurs, which happens with probability $\rho_{i}$. Appendix 1 shows that this reward can be written as:

$$
V_{i}^{\prime}=\frac{\left(\theta^{\prime}-1\right)}{\theta^{\prime}}\left(\frac{\left.\theta^{(1-\alpha)}-1\right)}{\theta^{(1-\alpha)}}\right) \sum_{s=t+1}^{\infty} Y_{s} d_{i s}
$$

where $d_{i s}$ is defined in the appendix. The right side of equation (2.15) is simply the discounted sum of all future production in the industry, with discounting inclusive of time and probabilities of loss of the profit stream in future periods.

We model the research firm as hiring labor inputs that are used to produce research tries. In the limit, with a continuous measure for the tries, the probability of success comes from a Poisson distribution. As shown in Lambson and Phillips (1999), this gives the following functional form for an industry's applied R\&D success probability:

$$
\rho_{i}=1-\exp \left\{-\kappa b_{i} L_{i}\right\}
$$


where $\kappa$ is the "ease" of doing research and $b_{i}$ is the ratio $B_{i} / A_{i}$ of basic to applied technology. Intuitively, the greater the ease of research, the higher is the success probability. And, following intuition discussed earlier, the higher is the stock of basic know-how in an industry, the greater the likelihood of success in applied research. Finally, note that in (2.16) increases in labor devoted to applied R\&D also raises the success probability.

In a symmetric equilibrium arising when all firms have the same probability function for $\rho_{i}$, the reward for success in (2.15) will be the same for all firms. All firms then face an identical problem. The solution to the problem is for the firm to hire the amount of labor it can afford, given the constraint from equity sales. Consequently, $q_{i}^{R}=w L_{i}$ for each industry and aggregate employment by all research firms is $L=I L_{i}$. In addition, since the expected revenue streams for all intermediate goods producers are the same, the prices of equities for all research and production firms are equal.

\section{$\underline{\text { Market-Clearing Conditions }}$}

In addition to the Euler equations from the household and firms' problems, market clearing conditions must be satisfied. Clearing of the labor and capital markets requires:

$$
\begin{aligned}
& \sum_{i=1}^{I}\left[L_{i}+N_{i}\right]=L+N=1 \\
& \sum_{i=1}^{I} K_{i}=K
\end{aligned}
$$

and clearing of equity markets requires:

$$
\begin{aligned}
& P=P^{\prime}=1 \\
& R=R^{\prime}=1
\end{aligned}
$$

With these conditions, Walras' law ensures goods market clearing.

\section{The Transformed Model}

The model economy experiences growth in consumption and output per household due to the

increases in $A$ over time. It will be convenient to work with a transformed model where the 
endogenous variables are all stationary. Since transformations to induce stationarity are commonly used, we delegate details to Appendix 2 and hereafter consider a transformed version of the model. Variables growing at the same rate as $A$ are transformed with division by $A$, and the transformed variables will be denoted with a caret so that, for example, $\hat{K} \equiv K / A$.

The transformed law of motion for $A$ is:

$$
g_{A}{ }^{\prime} \equiv A^{\prime} / A=\rho(\theta-1)+1+\varepsilon^{\prime}
$$

where $\varepsilon^{\prime}=[(J / I)-\rho](\theta-1), J$ is distributed Binomial $(I, \rho), E\left\{\varepsilon^{\prime}\right\}=0$, and $\operatorname{Var}\left\{\varepsilon^{\prime}\right\}=\frac{\rho(1-\rho)}{I}(\theta-1)^{2}$.

The transformed law of motion for $B$ is:

$$
g_{B}{ }^{\prime} \equiv B^{\prime} / B=\phi(\lambda-1)+1+v^{\prime}
$$

where $v^{\prime}=(H-\phi)(\lambda-1), H$ is distributed Poisson $(\phi), E\left\{v^{\prime}\right\}=0$, and $\operatorname{Var}\left\{v^{\prime}\right\}=\phi(\lambda-1)^{2}$. And, the law of motion for $z$ is:

$$
z^{\prime}=\psi z+\eta^{\prime}
$$

with $\eta^{\prime}$ distributed $\mathrm{N}\left(0, \sigma^{2}\right)$.

We consider a CES momentary utility function of the form $u(C)=\frac{1}{1-\gamma} C^{1-\gamma}$. Substituting for marginal utility and transforming household optimality conditions (2.1) - (2.3) gives:

$$
\begin{aligned}
& E \hat{C}\{\Gamma\}^{-\gamma} \hat{q}^{P}=\beta\left(g_{A}{ }^{\prime}\right)^{-\gamma}(1-\rho\{\Gamma\}) E \hat{C}\left\{\Gamma^{\prime}\right\}^{-\gamma}\left(\hat{\pi}\left\{\Gamma^{\prime}\right\}+\hat{q}^{P}\left\{\Gamma^{\prime}\right\}\right) \\
& E \hat{C}\{\Gamma\}^{-\gamma} \hat{q}^{R}=\beta\left(g_{A}{ }^{\prime}\right)^{-\gamma} \rho\{\Gamma\} E \hat{C}\left\{\Gamma^{\prime}\right\}^{-\gamma}\left(\hat{\pi}\left\{\Gamma^{\prime}\right\}+\hat{q}^{P}\left\{\Gamma^{\prime}\right\}\right) \\
& \hat{C}^{-\gamma}=\beta\left(g_{A}{ }^{\prime}\right)^{-\gamma} E \hat{C}\left\{\Gamma^{\prime}\right\}^{-\gamma}\left(1-\delta+r\left\{\Gamma^{\prime}\right\}\right)
\end{aligned}
$$

where $\Gamma^{\prime}=\left\{b^{\prime}, z^{\prime}, \hat{K}^{\prime}\right\}$ and $v\left(\Gamma^{\prime}\right)$ indicates dependence of variable $v$ on states $\Gamma^{\prime}$. Substituting (2.19) and (2.20) into the household's budget constraint and taking expectations gives:

$$
E \hat{C}=\hat{w}+(1-\delta+r) \hat{K}+\hat{\pi}-E\left\{\hat{K}^{\prime}\left(1+g_{A}{ }^{\prime}\right)\right\}-\hat{q}^{R}
$$

The additional transformed equations from firms' decisions are: 


$$
\begin{aligned}
& \hat{w}(1-L)=\frac{1-\alpha}{\theta^{1-\alpha}} \hat{K}^{\alpha}\left[e^{z}(1-L)\right]^{1-\alpha} \\
& r \hat{K}=\frac{\alpha}{\theta^{1-\alpha}} \hat{K}^{\alpha}\left[e^{z}(1-L)\right]^{1-\alpha} \\
& \hat{\pi}=\frac{\theta^{1-\alpha}-1}{\theta^{1-\alpha}} \hat{K}^{\alpha}\left[e^{z}(1-L)\right]^{1-\alpha} \\
& \rho=1-\exp \{-\kappa b L\} \\
& \hat{q}^{R}=\hat{w} L \\
& \phi=f L
\end{aligned}
$$

Equations (3.1) - (3.13) define the dynamic model that we solve, parameterize, and simulate. Because the highly nonlinear nature of the system makes closed form solutions intractable, we consider a linear approximation of the system about its steady state.

\section{Calibration and Simulation}

We solve the system using the method of undetermined coefficients developed in Christiano (1990). Because we approximate about the model's steady state, we first need to solve for the steady state. The parameters and their values are listed in table 2. There are eight parameters which define the steady state: $\alpha, \beta, \gamma, \delta, f, \kappa, \lambda$ and $\theta$. For consistency with existing RBC-model parameterizations, we set capital's share in output, $\alpha$, to .3, quarterly discount factor, $\beta$, to.995, depreciation rate, $\delta$, to .02 , and the autocorrelation coefficient on the $z$ shocks, $\psi$, to .95 .

$\theta$ and $\lambda$, the jumps up the two technology ladders, are both set to 1.05. $\kappa$ and $\gamma$ are chosen to exactly fix two steady state values, the average quarterly growth rate of real output, and the user cost of capital, $r-\delta$. We set average quarterly real growth equal to .005 , and $r-\delta$ to .0075 , for consistency with postwar averages in the U.S. economy, by setting $\kappa$ and $\gamma$ equal to 2.382 and .49312 , respectively. ${ }^{11}$ Since $A$ and $B$ must grow at the same rate in the steady state for constancy

11 To see how $\gamma$ is chosen, consider the steady state version of equation (3.6): 
of $b$, we set $b=1$ in steady state, which implies a value of 2.2659 for $f .{ }^{12}$ Given the parameter values we have assigned, the steady state probability of success in applied $R \& D$ is $\rho=.10$, which we take to be an empirically plausible and conservative value.

The standard deviation of technology shocks is set to .003, well below the value used in most RBC analyses. For example, using data from the U.S. economy in the post Bretton Woods era, Schlagenhauf and Wrase (1995) use a value of .014. The standard deviation in labor productivity shocks in the production firms' technologies that we use is an entire order of magnitude below that used in RBC models! One of our objectives is to see how the model, with substantially less reliance on productivity shocks than standard RBC models, performs in accounting for business cycle fluctuations observed in key macroeconomic variables. Given the parameter values we use the standard deviation of the innovations to basic $R \& D$ in (3.2) and to applied R\&D in (3.1) is .016, of the order of magnitude used for productivity shocks in RBC models. We are not, however, simply assuming the variability of the $R \& D$ innovations. The variability of innovations to the evolution of applied research in (3.1) depends on the probability of success in R\&D. In turn, the success probability depends endogenously on labor choices made by R\&D firms and households in the model.

$$
1=\beta\left(\bar{g}_{A}\right)^{-\gamma}(1-\delta+\bar{r})
$$

Note that it is necessary to pick a value of $\beta$ sufficiently large if we are to generate positive values for $\gamma$. Since $A$ and $B$ must grow at the same rate in the steady state if $b$ is to remain constant this pins down a value of 2.2659 for $f$.

$12 \theta$ must equal $\rho$ in the steady state. Since the growth rates of basic and applied R\&D must be equal, $\rho$ and $\phi$ must also be equal. The values assigned to $\theta$ and $\kappa$, along with $b=1$, gives a steady state value of $\rho$. That value, given the functional form in (2.16) for success probability $\rho$, pins down the steady state value of $L$ for an industry. Then, since $L=\phi / f$ from (3.13), the steady state value for $f$ can be found. 
We cannot simply choose the standard deviation of innovations in applied R\&D without restriction. One restriction is that the probability of success in the model must be an empirically plausible value.

Note that the model generates a series of growth rates. We can use these to construct a series for the level of technology, the $A$ 's, and then convert all the stationary, caret-bearing, variables to their non-stationary counterparts. Hence, simulation of the model generates data with both cyclical and growth components.

The model was simulated 100 times using a sample of 200 observations, corresponding to 50 years of data. We filter both actual data drawn from the U.S. economy and model-generated data using two filters: the Hodrick-Prescott (HP) filter; and, to consider movements of variables at other than simply business cycle frequencies, a band-pass filter. We then compute statistical properties of the data, and compare properties of model-generated data with like properties of actual data. We focus on standard RBC measures of variability, cyclicality, and persistence, but consider more than the business cycle frequencies that are the sole focus of RBC analyses.

\section{Quantitative Results}

Table 3a presents business cycle moments summarizing behaviors of key macroeconomic aggregates for the U.S. economy over a sample period 1957:Q1 to 1998:Q2.13 As is well known, and as revealed in the table, investment is close to four times as variable as output, with variability measured by standard deviations. Consumption has only three-quarters the variability of output. In addition, output is highly serially correlated, consumption is highly correlated with output contemporaneously and at one to two period leads and lags, and investment is not strongly correlated with output contemporaneously or at leads and lags.

As a first step in evaluating the model's quantitative properties, we consider the ability to account for the basic summary statistics for the U.S. economy presented in Table 3a. The data used to construct the table are deviations from trend, where the trend is obtained using the HP filter. The

13 The data are real GDP, real consumption, and real gross fixed investment taken from the International Monetary Funds International Financial Statistics. 
movements in variables captured in the table are best thought of as movements at business cycle frequencies.

Comparing moments of actual and model-generated data has been common for evaluating variants of the Solow's basic exogenous growth model in the $\mathrm{RBC}$ literature. As Table $3 \mathrm{~b}$ reveals, the endogenous growth model does a remarkably good job of approximating data properties observed in the actual U.S. economy. And, the close approximation obtains even though we have employed RBCstyle, exogenous productivity shocks with standard deviations one order of magnitude below what is used in standard exogenous-growth RBC models. Alternatively stated, relative to the endogenous growth model that we have constructed, an RBC model requires exogenous technology shocks that are an order of magnitude more variable than what we have used to account for the business cycle statistics shown in Table 3a.

Table $3 \mathrm{a}$ reveals that investment in the model is close to three-and-a-half times more variable than output, consumption is close to three-quarters as variable as output, and output is highly serially correlated. Investment in the model is, however, more strongly correlated with output than in the actual data, and consumption is not as strongly correlated in the model as in actual data.

The model accounts not only for the quarter-to-quarter variations in variables picked up in the variability and correlation statistics commonly considered in evaluating RBC models. In contrast to RBC models in which trend and long-term movements in economic variables are exogenous, the dynamic Schumpeterian model in this paper also accounts for long-term data movements. Is it potentially important? Indeed, as identified by Granger (1966) and Sargent (1987), the typical spectral shape of macroeconomic time series is one with substantial power in a significant range of low frequencies. Consequently, it is of interest to also compare fluctuations in data and in the model at other than the business cycle frequencies considered in Table 3a. In particular, it is of interest to determine how the model performs in accounting for long-run movements observed in actual data. We do this by passing actual and model-generated data through the band-pass filter 
developed in Baxter and King (1998) to highlight properties of series at alternative horizons. The results are shown in Table $3 b$.

Table $3 \mathrm{~b}$ shows moments of data filtered in various ways. The first set of moments is for deviations from trend in actual and model-generated data, where the trend is obtained using the HP filter with a standard value of 1600 used for the smoothing parameter. As before, these moments pick up movements in data at frequencies that roughly correspond to business cycles. The other sets of moments are for data passed through Baxter and King's band-pass (BP) filter, focusing on fluctuations at alternative frequencies. In the notation of Baxter and King (1998), we use an approximate BP filter with $\mathrm{K}=12$ truncations at leads and lags. $\mathrm{K}=12$ is chosen in face of the tradeoff between loss of observations and reductions in leakage and compression from increases in $\mathrm{K}$. The numbers inside parentheses in $\mathrm{BP}(.,$.$) identify the frequencies that the filter isolates. { }^{14}$ For example, for $\mathrm{BP}(6,32)$ the filter passes through cycles of length between 6 and 32 quarters, roughly the business cycle frequencies picked up by the HP filter. $\mathrm{BP}(2,6)$ passes through cycles of length between 2 and 6 quarters and, hence, isolates very high frequency fluctuations. BP(20,80) passes through cycles of length between 20 and 80 quarters and, therefore, fluctuations occurring at lower frequencies than typically considered in RBC studies.

In both the model and actual data, looking at the $\mathrm{BP}(2,6)$ results, at very high frequencies investment is over six times as variable as output, and consumption variability is far lower than investment. The model provides a slight overstatement of consumption variability. Overall, the pattern in the model of correlations of investment and consumption with output contemporaneously and at leads and lags generally follows the pattern observed in the U.S. data. However, investment is more strongly correlated with output contemporaneously and leads next periods output more

${ }^{14}$ In the notation of Baxter and King, with p denoting the shortest cycle length (in quarters) passed by the filter, and q denoting the longest cycle length, these numbers correspond to the $\mathrm{BP}_{\mathrm{K}=12}(\mathrm{p}, \mathrm{q})$ filter, with $(\mathrm{p}, \mathrm{q})$ set to $(2,6),(6,32)$, and $(20,80)$. 
strongly than in actual data. The model also has consumption being negatively correlated with consumption at the high frequencies, counter to what we see in the actual data. And, for output itself, there is a stronger correlation between current output and output at a one period lead and lag in the model relative to actual data. Given that the model is not constructed to account for the very high frequency data movements isolated by the $\mathrm{BP}(2,6)$ filter, though, the model seems to account for the data fairly well.

Turning to the results of $\mathrm{BP}(6,32)$, qualitatively the comparison of model-generated data with actual data is not very different from the comparison when the HP filter is used. This is not surprising, since both filters focus on fluctuations at business cycle frequencies. At these frequencies, relative to actual data the model's investment series is less volatile and more strongly correlated with output. Using the $\mathrm{BP}(6,32)$ filter, consumption now appears somewhat less volatile in the model than in the data. ${ }^{15}$ Evidently, incentives for consumption smoothing by agents in the model, as currently parameterized, are not sufficiently strong for the consumption to be as smooth as the actual data counterpart.

Consumption in the $\mathrm{BP}(6,32)$ view of model-generated data is more strongly correlated with output contemporaneously and at leads and lags relative to the HP filtered view, moving the model closer to actual data. However, as with the HP filtered results, the correlation between consumption and output in the model are lower than in actual data. This is true for the contemporaneous correlation between consumption and output, and for correlations between current consumption and various leads and lags of output. Considering, again, the $\mathrm{BP}(6,32)$ filtered results, investment in the model is slightly less variable relative to output compared to the same relative variability in actual data. Relative to actual data investment in the model is also more strongly correlated with

15 The reduction in volatility of consumption in the model relative to actual data is not as pronounced when the HP filter is used. This follows because the HP filter passes through some of the high frequency fluctuations found in consumption in the $\mathrm{BP}(2,6)$ filtered series, while the $\mathrm{BP}(6,32)$ filter does not. 
contemporaneous and lagged output. And, in contrast to actual data, the correlation of investment with future output in the model is strong and positive.

The magnitudes and pattern of correlations between current output and output at various leads and lags implied by the model are extremely close to what we observe in actual data. This is remarkable given that the model relies far less on highly persistent shocks to labor productivity than a standard RBC model.

Given that the model endogenously accounts for growth and, therefore, low frequency data movements, as well as business cycles, it is of particular interest to consider results when data are passed through the $\mathrm{BP}(20,80)$ filter. These results provide perspective on long-term fluctuations in the data, some of which are filtered out in the other bandwidths considered in Table $3 \mathrm{~b}$ and in the HP filtered data. For actual U.S. data, it remains that investment is over three times as volatile as output, and that consumption is slightly less volatile than output. While the relative volatilities implied by the model are close to their actual data counterparts, investment and consumption, as at business cycle frequencies, remain smoother that in actual data.

In the U.S. data, using the $\mathrm{BP}(20,80)$ filter, the correlation of investment with contemporaneous output remains positive, but is stronger over the long-term than in the other frequencies we have considered. This is also true in the model. However, the model continues to imply counterfactually stronger correlations between current investment and current output and output at leads and lags than in actual data. The positive correlation between current investment and current and lagged values of output remains positive in actual data, as in the filtered data where business cycle fluctuations were the focus. But allowing for longer-term movements appears to make current investment more strongly correlated with current and past output. This is also true of consumption in the actual data and in the model. The model, when looking at relatively low frequency fluctuations, implies magnitudes and a pattern of correlations between current consumption and current, lagged, and future output levels that are closer to what is observed in actual data than is true when considering business cycle frequencies. It evidently takes more time for agents in the model to generate smooth consumption sequences than in the actual economy. 
While evidence of consumption smoothing shows up at business cycle frequencies in the model, at those frequencies consumption is not as strongly correlated with output as in the data. However, looking at longer-term movements, the correlations between current consumption and output of various periods move closer to their counterparts in the actual data. For correlations of current output with output of various leads and lags, the remarkable correspondence between the model and actual data remains at low frequencies.

Overall, the model does a fairly good job of accounting for many of the facts RBC models have addressed in the past. It also performs well in accounting for data movements at longer than business cycle frequencies. While consumption and investment in the model are less volatile at business cycle and longer frequencies than in actual data, the discrepancy is not large.

The two biggest discrepancies between the model and actual data appear to be in the patterns of correlations between both current investment and current consumption and current, lagged, and future values of output. The correlations between current investment and current, lagged, and future output in the model are much stronger than in actual data at business cycle and longer frequencies. The same correlations for current consumption in the model are weaker than in actual data at business cycle frequencies. The model performs remarkably well, however, in accounting for correlations between output in a period and output at various leads and lags, even though the model does not rely heavily on highly persistent RBC-style productivity shocks.

\section{Conclusion}

Our objective in this paper has been to construct a discrete-time dynamic general equilibrium Schumpeterian model containing endogenous growth through $R \& D$, and to determine whether the model is capable of accounting for key features of fluctuations in data drawn from the U.S. economy at business cycle and longer frequencies. Quantitative analysis of a parameterized version of the model reveals that it is capable of accounting for key features of fluctuations in macroeconomic variables at various frequencies. Moreover, the model can do so without relying as heavily on highly persistent and variable exogenous shocks to technology as standard RBC models. 
It is of interest to consider sensitivity of the model's quantitative implications to perturbations in values of parameters in the model. It is also of interest to determine just how far the model can further abstract from persistence and volatility in the RBC-style shocks and still account for properties of actual U.S. data. This will enable us to see the extent to which endogenous Schumpeterian innovations can replace exogenous RBC-style productivity shocks in accounting for aggregate economic fluctuations. It will also be useful to compare a standard RBC model with the Schumpeterian model's ability to account for low-frequency fluctuations in actual data on macroeconomic aggregates. These are topics of current investigation. 


\section{Table 1}

\section{Definition of Variables}

Endogeous variables that change over time:

$A_{i} \quad$ level of technology in intermediate industry $i$.

$A_{i} \quad$ level of applied knowledge in intermediate industry $i$.

$B_{i} \quad$ level of basic knowledge in intermediate industry $i$.

$A \quad$ aggregate level of applied knowledge.

$B \quad$ aggregate level of basic knowledge.

$b_{i} \quad$ ratio of $A_{i}$ to $\mathrm{B}_{i}$ in intermediate industry $i$.

$b \quad$ ratio of aggregate $A$ to $B$.

$z \quad$ RBC-style productivity shock.

$K \quad$ capital stock owned by household.

$K_{i} \quad$ capital employed in industry $i$.

$P_{i} \quad$ shares of production firm $i$ owned by household.

$R_{i} \quad$ shares of research firm $i$ owned by household.

$S_{i} \quad$ state of research success for industry $i$; 1 is success, 0 is failure.

$w$ real wage.

$r \quad$ real interest rate.

$L_{i} \quad$ labor hired by research firm $i$.

$N_{i} \quad$ labor hired by production firm $i$.

$Y_{i} \quad$ output of intermediate good $i$.

$Y \quad$ output of final goods.

$p_{i} \quad$ price of intermediate good $i$.

$\pi_{i} \quad$ profits earned by current production firm $i$.

$q_{i}^{P} \quad$ price of one share in the current production firm $i$.

$q_{i}^{R} \quad$ price of one share in the current research firm $i$.

$\rho_{i} \quad$ probability that $S_{i}=1$.

$J \quad$ number of industries that succesfully innovate; $J \leq I$.

$H$ number of innovations in $B$.

Ix1 vectors:

A vector of $A_{i}$ 's.

B vector of $B_{i}$ 's.

S vector of $S_{i}$ 's.

$\mathbf{P} \quad$ vector of $P_{i}^{\prime}$ 's.

$\mathbf{R} \quad$ vector of $R_{i}^{\prime}$ 's.

$\mathbf{q}^{P} \quad$ vector of $q_{i}^{P}$ 's.

$\mathbf{q}^{R} \quad$ vector of $q_{i}^{R}$ 's.

$\rho \quad$ vector of $\rho_{i}$ 's.

\section{Parameters:}

$\alpha \quad$ capital share in output from a Cobb-Douglas production function; $0<\alpha<1$.

$\theta \quad$ growth factor for $A_{i}$ when $S_{i}=1 ; \theta>1$.

$\lambda \quad$ growth factor for $B ; \lambda>1$.

f $\quad$ sensitivity of $B$ to R\&D inputs; $f>0$.

$\delta \quad$ rate of depreciation; $\delta>0$.

$\beta \quad$ time discount factor; $\beta<1$.

$\gamma \quad$ CES parameter from momentary utility function; $\gamma \geq 0$.

$\psi \quad$ autocorrelation parameter for $z$. 
variance of innovations in $z$. 
Table 2

Values of arameters used in Simulation

\begin{tabular}{|l|l|l|}
\hline \multicolumn{1}{|c|}{ arameter } & Description & Value \\
\hline$\alpha$ & Capital share in GDP & 0.30 \\
\hline$\beta$ & Time discount factor for utility & 0.99 \\
\hline$\delta$ & Depreciation rate & 0.02 \\
\hline$F$ & Sensitivity of B to R\&D employment & 2.27 \\
\hline$\lambda$ & Size of rungs on the basic technology ladder & 1.05 \\
\hline$\theta$ & Size of rungs on the applied technology ladder & 1.05 \\
\hline$\gamma$ & Elasticity of substitution & 0.49 \\
\hline$\kappa$ & Ease of R\&D & 2.39 \\
\hline$\psi$ & Autocorrelation for $z$ shocks & 0.95 \\
\hline
\end{tabular}


Table 3a

$\begin{array}{lllllll}\text { Business Cycle Moments from } & \text {.S. Data } & 1 & 5 & \text { :Q1 } & 1 & \text { :Q2 }\end{array}$

\begin{tabular}{|l||c|c|c|}
\hline \multicolumn{1}{|l||}{} & $\boldsymbol{Y} \boldsymbol{I} \boldsymbol{\boldsymbol { T }}$ & $\mathbf{C} \boldsymbol{\mathbf { 0 . 0 1 1 }}$ \\
\hline \hline ST DEV & $\mathbf{0 . 0 1 5}$ & $\mathbf{0 . 0 5}$ & $\mathbf{0 . 5 2}$ \\
\hline Relative & $\mathbf{1 . 0 0 0}$ & $\mathbf{3 . 0 5 1}$ & 0.4199 \\
\hline CORR Y LAG -4 & 0.2415 & 0.0932 & 0.5711 \\
\hline CORR Y LAG -3 & 0.4470 & 0.0597 & 0.7245 \\
\hline CORR Y LAG -2 & 0.6652 & 0.0181 & 0.8337 \\
\hline CORR Y LAG -1 & 0.8575 & 0.0352 & $\mathbf{0 .} \mathbf{4 5}$ \\
\hline CORR LAG 0 & $\mathbf{1 . 0 0 0}$ & $\mathbf{0 . 1 4 5 0}$ & 0.7138 \\
\hline CORR Y LAG 1 & 0.8566 & 0.2070 & 0.5441 \\
\hline CORR Y LAG 2 & 0.6567 & 0.1997 & 0.3464 \\
\hline CORR Y LAG 3 & 0.4276 & 0.1968 & 0.1618 \\
\hline CORR Y LAG 4 & 0.2163 & 0.2411 & \\
\hline
\end{tabular}

* Source: International Monetary Fund's International Financial Statistics. 
Table 3a, continued.

\section{Business Cycle Moments from Simulations}

\begin{tabular}{|l||c|c|c|}
\hline VARIABLE & $\boldsymbol{Y}$ & $\boldsymbol{I}$ & $\boldsymbol{C}$ \\
\hline \hline ST DEV & $\mathbf{0 . 0 1 5 2}$ & $\mathbf{0 . 0 5 1 2}$ & $\mathbf{0 . 0 1 1}$ \\
\hline Relative & $\mathbf{1 . 0 0 0 0}$ & $\mathbf{3 . 3 5} \mathbf{4}$ & $\mathbf{0 .}$ \\
\hline CORR Y LAG -4 & 0.1127 & 0.0657 & 0.0919 \\
\hline CORR Y LAG -3 & 0.3192 & 0.1949 & 0.2389 \\
\hline CORR Y LAG - & 0.5516 & 0.3728 & 0.3548 \\
\hline CORR Y LAG - & 0.7631 & 0.4700 & 0.5694 \\
\hline CORR LAG 0 & $\mathbf{1 . 0 0 0 0}$ & $\mathbf{0 . 3 0 0}$ & $\mathbf{0 . 4 0 5 3}$ \\
\hline CORR Y LAG 1 & 0.7642 & 0.5619 & 0.4360 \\
\hline CORR Y LAG 2 & 0.55355 & 0.4026 & 0.3270 \\
\hline CORR Y LAG 3 & 0.32239 & 0.2173 & 0.2232 \\
\hline CORR Y LAG 4 & 0.11523 & 0.0088 & 0.2005 \\
\hline
\end{tabular}

* Data are generated by simulating the model using parameter values given in the main text (with $\mathrm{I}=1, \sigma^{2}=.001$ ). The data are from 100 simulations, each of which generates 199 observations. 


\section{Figure 3b}

\section{U.S. Data 1962:III-1997:II}

HP
\begin{tabular}{|l|l|l|l|}
\hline VARIABLE & $\boldsymbol{Y}_{t}$ & $\boldsymbol{I}_{t}$ & $\boldsymbol{C}_{t}$ \\
\hline ST DEV & $\mathbf{0 . 0 1 5 6}$ & $\mathbf{0 . 0 5 7 8}$ & $\mathbf{0 . 0 1 1 8}$ \\
\hline Relative & $\mathbf{1 . 0 0 0 0}$ & $\mathbf{3 . 7 0 5 1}$ & $\mathbf{0 . 7 5 2 6}$ \\
\hline CORR $Y_{t+3}$ & 0.4470 & -0.0597 & 0.5711 \\
\hline CORR $Y_{t+2}$ & 0.6653 & -0.0182 & 0.7245 \\
\hline CORR $Y_{t+1}$ & 0.8575 & 0.0352 & 0.8338 \\
\hline CORR $Y_{t}$ & $\mathbf{1 . 0 0 0 0}$ & $\mathbf{0 . 1 4 5 0}$ & $\mathbf{0 . 8 6 4 2}$ \\
\hline CORR $Y_{t-1}$ & 0.8567 & 0.2071 & 0.1392 \\
\hline CORR $Y_{t-2}$ & 0.6567 & 0.1998 & 0.5441 \\
\hline CORR $Y_{t-3}$ & 0.4277 & 0.1969 & 0.3464 \\
\hline
\end{tabular}

Baxter-King BP(2,6)

\begin{tabular}{|l||l|l|l|}
\hline VARIABLE & $\boldsymbol{V}_{t}$ & $\boldsymbol{t}_{t}$ & $\boldsymbol{C}_{\boldsymbol{t}}$ \\
\hline ST DEV & $\mathbf{0 . 0 0 4 2}$ & $\mathbf{0 . 0 2 8 0}$ & $\mathbf{0 . 0 0 3 8}$ \\
\hline Relative & $\mathbf{1}$ & $\mathbf{6 . 5 6 8 3}$ & $\mathbf{0 . 8 9 6 3}$ \\
\hline CORR $\mathrm{Y}_{\mathrm{t+3}}$ & -0.2417 & -0.1974 & -0.2569 \\
CORR $\mathrm{Y}_{\mathrm{t}+2}$ & -0.3887 & -0.1320 & -0.1496 \\
\hline CORR $\mathrm{Y}_{t+1}$ & -0.0945 & -0.0801 & 0.1913 \\
\hline CORR $\mathbf{Y}_{t}$ & $\mathbf{1 . 0 0 0 0}$ & $\mathbf{0 . 3 0 9 1}$ & $\mathbf{0 . 5 5 4 7}$ \\
\hline CORR $\mathrm{Y}_{t-1}$ & -0.0944 & 0.2095 & -0.2401 \\
\hline CORR $\mathrm{Y}_{t-2}$ & -0.3827 & -0.2450 & -0.1981 \\
\hline CORR $\mathrm{Y}_{t-3}$ & -0.2366 & -0.3049 & -0.0842 \\
\hline
\end{tabular}

Baxter-King BP(6,32)

\begin{tabular}{|l|l|l|l|}
\hline VARIABLE & $\boldsymbol{Y}_{t}$ & $\boldsymbol{I}_{t}$ & $\boldsymbol{C}_{t}$ \\
\hline \hline ST DEV & $\mathbf{0 . 0 1 4 1}$ & $\mathbf{0 . 0 4 5 3}$ & $\mathbf{0 . 0 1 0 2}$ \\
\hline Relative & $\mathbf{1}$ & $\mathbf{3 . 2 0 3 9}$ & $\mathbf{0 . 7 2 8 0}$ \\
\hline CORR $\mathrm{Y}_{\mathrm{t}+3}$ & 0.4645 & -0.1359 & 0.6103 \\
\hline CORR $\mathrm{Y}_{\mathrm{t}+2}$ & 0.7305 & -0.0841 & 0.7958 \\
\hline CORR $\mathrm{Y}_{\mathrm{t}+1}$ & 0.9270 & -0.0264 & 0.9071 \\
\hline CORR $\mathbf{Y}_{\mathrm{t}}$ & $\mathbf{1 . 0 0 0 0}$ & $\mathbf{0 . 0 4 1 3}$ & $\mathbf{0 . 9 0 9 2}$ \\
\hline CORR $\mathrm{Y}_{\mathrm{t}-1}$ & 0.9267 & 0.1205 & 0.7913 \\
\hline CORR $\mathrm{Y}_{\mathrm{t}-2}$ & 0.7294 & 0.2072 & 0.5779 \\
CORR $\mathrm{Y}_{\mathrm{t}-3}$ & 0.4635 & 0.2918 & 0.3192 \\
\hline
\end{tabular}

Baxter-King $\mathrm{BP}(\mathbf{2 0 , 8 0})$

\begin{tabular}{|l||l|l|l|}
\hline VARIABLE & $\boldsymbol{Y}_{t}$ & $\boldsymbol{I}_{t}$ & $\boldsymbol{C}_{t}$ \\
\hline ST DEV & $\mathbf{0 . 0 1 3 4}$ & $\mathbf{0 . 0 4 0 5}$ & $\mathbf{0 . 0 1 1 1}$ \\
\hline Relative & $\mathbf{1}$ & $\mathbf{3 . 0 1 5 7}$ & $\mathbf{0 . 8 3 0 0}$ \\
CORR $\mathrm{Y}_{t+3}$ & 0.7830 & -0.1488 & 0.8501 \\
\hline CORR $\mathrm{Y}_{t+2}$ & 0.9006 & -0.0346 & 0.9313 \\
\hline CORR $\mathrm{Y}_{t+1}$ & 0.9746 & 0.0864 & 0.9688 \\
\hline CORR $\mathbf{Y}_{t}$ & $\mathbf{1 . 0 0 0 0}$ & $\mathbf{0 . 2 0 5 5}$ & $\mathbf{0 . 9 6 1 3}$ \\
\hline CORR $\mathrm{Y}_{\mathrm{t}-1}$ & 0.9749 & 0.3125 & 0.9095 \\
\hline CORR $\mathrm{Y}_{\mathrm{t}-2}$ & 0.9022 & 0.3996 & 0.8175 \\
\hline CORR $\mathrm{Y}_{\mathrm{t}-3}$ & 0.7879 & 0.4608 & 0.6914 \\
\hline
\end{tabular}

Model-Generated Data (100 Simulations, 199 Observations)

HP
\begin{tabular}{|l||l|l|l|}
\hline VARIABLE & $\boldsymbol{Y}_{\boldsymbol{t}}$ & $\boldsymbol{I}_{t}$ & $\boldsymbol{C}_{t}$ \\
\hline ST DEV & $\mathbf{0 . 0 1 5 3}$ & $\mathbf{0 . 0 5 1 3}$ & $\mathbf{0 . 0 1 1 8}$ \\
\hline relative & $\mathbf{1 . 0 0 0 0}$ & $\mathbf{3 . 3 5 8 4}$ & $\mathbf{0 . 7 7 5 2}$ \\
\hline CORR $\mathrm{Y}_{\mathrm{t}+3}$ & 0.3193 & 0.1949 & 0.2390 \\
\hline CORR $Y_{\mathrm{t}+2}$ & 0.5516 & 0.3729 & 0.3548 \\
\hline CORR $\mathrm{Y}_{\mathrm{t}+1}$ & 0.7632 & 0.4700 & 0.5695 \\
\hline CORR & $\mathbf{1 . 0 0 0 0}$ & $\mathbf{0 . 8 3 0 0}$ & $\mathbf{0 . 4 0 5 3}$ \\
\hline CORR $\mathrm{Y}_{\mathrm{t}-1}$ & 0.7642 & 0.5619 & 0.4368 \\
\hline CORR $\mathrm{Y}_{\mathrm{t}-2}$ & 0.5536 & 0.4026 & 0.3270 \\
\hline CORR $\mathrm{Y}_{\mathrm{t}-3}$ & 0.3224 & 0.2174 & 0.2232 \\
\hline
\end{tabular}

Baxter-King $\mathbf{B P}(\mathbf{2}, \mathbf{6})$

\begin{tabular}{|l|l|l|l|}
\hline VARIABLE & $\boldsymbol{V}_{\boldsymbol{t}}$ & $\boldsymbol{t}_{t}$ & $\boldsymbol{C}_{\boldsymbol{t}}$ \\
\hline \hline ST DEV & $\mathbf{0 . 0 0 5 4}$ & $\mathbf{0 . 0 3 3 6}$ & $\mathbf{0 . 0 0 9 2}$ \\
\hline relative & $\mathbf{1 . 0 0 0 0}$ & $\mathbf{6 . 2 3 5 0}$ & $\mathbf{1 . 7 1 0 4}$ \\
\hline CORR $\mathrm{Y}_{\mathrm{t}+3}$ & -0.0055 & -0.0652 & 0.0811 \\
\hline CORR $\mathrm{Y}_{\mathrm{t}+2}$ & -0.3471 & -0.0927 & -0.1471 \\
\hline CORR $\mathrm{Y}_{\mathrm{t}+1}$ & -0.2806 & -0.3213 & 0.1791 \\
\hline CORR $\mathbf{Y}_{t}$ & $\mathbf{1 . 0 0 0 0}$ & $\mathbf{0 . 6 4 1 9}$ & $\mathbf{- 0 . 0 3 9 9}$ \\
\hline CORR $\mathrm{Y}_{\mathrm{t}-1}$ & -0.2812 & -0.2030 & 0.0509 \\
\hline CORR $\mathrm{Y}_{\mathrm{t}-2}$ & -0.3466 & -0.0498 & -0.2142 \\
\hline CORR $\mathrm{Y}_{\mathrm{t}-3}$ & -0.0057 & -0.1260 & 0.1620 \\
\hline
\end{tabular}

Baxter-King BP(6,32)

\begin{tabular}{|l||l|l|l|}
\hline VARLABLE & $\boldsymbol{Y}_{t}$ & $\boldsymbol{I}_{t}$ & $\boldsymbol{C}_{t}$ \\
\hline ST DEV & $\mathbf{0 . 0 1 3 4}$ & $\mathbf{0 . 0 3 6 3}$ & $\mathbf{0 . 0 0 8 5}$ \\
\hline relative & $\mathbf{1 . 0 0 0 0}$ & $\mathbf{2 . 7 1 4 5}$ & $\mathbf{0 . 6 3 8 1}$ \\
\hline CORR $Y_{\mathrm{t}+3}$ & 0.4300 & 0.4406 & 0.2115 \\
\hline CORR $\mathrm{Y}_{\mathrm{t}+2}$ & 0.7026 & 0.6688 & 0.4321 \\
\hline CORR $\mathrm{Y}_{\mathrm{t}+1}$ & 0.9180 & 0.8421 & 0.6182 \\
\hline CORR $\mathrm{Y}_{\mathrm{t}}$ & $\mathbf{1 . 0 0 0 0}$ & $\mathbf{0 . 9 0 1 5}$ & $\mathbf{0 . 6 7 0 0}$ \\
\hline CORR $\mathrm{Y}_{\mathrm{t}-\mathrm{t}}$ & 0.9186 & 0.8258 & 0.6464 \\
\hline CORR $\mathrm{Y}_{\mathrm{t}-2}$ & 0.7064 & 0.6408 & 0.4881 \\
\hline CORR $\mathrm{Y}_{\mathrm{t}-3}$ & 0.4382 & 0.4025 & 0.2968 \\
\hline
\end{tabular}

Baxter-King BP(20,80)

\begin{tabular}{|l||l|l|l|}
\hline VARIABLE & $\boldsymbol{Y}_{\boldsymbol{t}}$ & $\boldsymbol{I}_{\boldsymbol{t}}$ & $\boldsymbol{C}_{\boldsymbol{t}}$ \\
\hline ST DEV & $\mathbf{0 . 0 1 3 8}$ & $\mathbf{0 . 0 3 3 1}$ & $\mathbf{0 . 0 0 8 5}$ \\
\hline relative & $\mathbf{1 . 0 0 0 0}$ & $\mathbf{2 . 3 9 3 8}$ & $\mathbf{0 . 6 1 4 2}$ \\
\hline CORR $\mathrm{Y}_{\mathrm{t}+3}$ & 0.7424 & 0.7878 & 0.5173 \\
\hline CORR $\mathrm{Y}_{\mathrm{t}+2}$ & 0.8806 & 0.8908 & 0.6771 \\
\hline CORR $\mathrm{Y}_{\mathrm{t}+1}$ & 0.9691 & 0.9428 & 0.7999 \\
\hline CORR $\mathrm{Y}_{t}$ & $\mathbf{1 . 0 0 0 0}$ & $\mathbf{0 . 9 3 7 8}$ & $\mathbf{0 . 8 7 6 3}$ \\
\hline CORR $\mathrm{Y}_{\mathrm{t}-1}$ & 0.9688 & 0.8729 & 0.9008 \\
\hline CORR $\mathrm{Y}_{\mathrm{t}-2}$ & 0.8783 & 0.7525 & 0.8728 \\
\hline CORR $\mathrm{Y}_{\mathrm{t}-3}$ & 0.7360 & 0.5864 & 0.7951 \\
\hline
\end{tabular}




\section{Appendi 1}

The reward for success can be written as the expected present value of the profit stream, where this stream is discounted both by the real interest rate and by the probability of losing the monopoly to a newly successful research firm.

$$
V_{i}^{\prime}=\pi_{i}{ }^{\prime}+q_{i}^{p}{ }^{\prime}=\sum_{s=t+1}^{\infty} \pi_{i, s} d_{i, s} ; d_{i, s}=\prod_{u=1}^{s} \frac{1-\rho_{i, u}}{1+r_{u+1}}
$$

where the second subscript, used in the summation and product, indicates the time period.

Future profits are a constant fraction, $(\theta-1) / \theta$, of production. The level of technology, $\theta^{\star} A_{i}$, does not change as long as the firm is the monopoly producer. Consequently, we can rewrite the success reward as:

$$
V_{i}^{\prime}=\frac{\theta-1}{\theta} \sum_{s=t+1}^{\infty} Y_{s} d_{i, s}=\frac{\theta-1}{\theta} \text { or } V_{i}^{\prime}=\frac{(\theta-1)}{\theta} M_{i} ; \quad M_{i} \equiv \sum_{s=t+1}^{\infty} Y_{s} d_{i, s} .
$$

Since $M$ changes as aggregate output rises, with large $I$ large the expected effects of success or failure by any given research firm on $M$ will be small. Note also that $M$ will be the same for all research firms as long as $\rho$ is the same. There may be more than one solution to the system of equations that jointly determine the $M$ s and $\rho$ 's for all firms, but one solution is the symmetric one, where $M$ and $\rho$ are constant over time. 


\section{Appendi 2}

In order to induce stationarity, we take all the variables which grow at the same rate as $A$ in the previous section and divide them by $A$. This gives the following stationary variables:

$$
\begin{array}{cccc}
\hat{C} \equiv C / A & \hat{K} \equiv K / A \quad \hat{w} \equiv w / A & \hat{q}^{R} \equiv q^{R} / A \quad \hat{q}^{P} \equiv q^{P} / A \quad \hat{\pi} \equiv \pi / A \\
& g_{A}^{\prime} \equiv \tilde{A}^{\prime} / A .
\end{array}
$$

The transformed law of motion for $A$ can be written: $g_{A}{ }^{\prime} \equiv A^{\prime} / A=\rho(\theta-1)+1+\varepsilon^{\prime}$, where $\varepsilon^{\prime}=[(J / I)-\rho](\theta-1)$, and $J$ is distributed Binomial $(I, \rho)$. Note that $E\left\{\varepsilon^{\prime}\right\}=0$ and $\operatorname{Var}\left\{\varepsilon^{\prime}\right\}=\frac{\rho(1-\rho)}{I}(\theta-1)^{2}$. The transformed law of motion for $B$ is: $g_{B}{ }^{\prime} \equiv B^{\prime} / B=\phi(\lambda-1)+1+v^{\prime}$ where $v^{\prime}=(H-\phi)(\lambda-1)$, and $H$ is distributed Poisson $(\phi)$. Note that $E\left\{v^{\prime}\right\}=0$ and $\operatorname{Var}\left\{v^{\prime}\right\}=\phi(\lambda-1)^{2}$. The law of motion for $z$ is: $z^{\prime}=\psi z+\eta^{\prime}$, where $\eta^{\prime}$ is distributed Normal $\left(0, \sigma^{2}\right)$.

Substituting (2.19) and (2.20) into the household's budget constraint, and transforming variables, gives: $\hat{C}=\hat{w}+(1-\delta+r) \hat{K}+\hat{\pi}-\hat{K}^{\prime}\left(1+g_{A}{ }^{\prime}\right)-\hat{q}^{R}$, with expected consumption when the ousehold makes it's share decisions given by: $E \hat{C} \equiv E\{\hat{C}\}=\hat{w}+(1-\delta+r) \hat{K}+\hat{\pi}-E\left\{\hat{K}^{\prime}\left(1+g_{A}^{\prime}\right)\right\}-\hat{q}^{R}$. 


\section{References}

Aghion, P. and P. Howitt (1992), "A Model of Growth through Creative Destruction," Econometrica, vol. 60 , no. 2 pp. $323-51$.

Aghion, P. and P. Howitt (1998), Endogenous Growth Theory, MIT Press.

Andolfatto, D. and G.M. MacDonald (1998), "Technology Diffusion and Aggregate Dynamics," Review of Economic Dynamics, vol. 1, pp. 338-70.

Baxter, M. and R.G. King (1998), "Measuring Business Cycles: Approximate Band-Pass Filters for Economic Time Series," University of Virginia working paper.

Christiano, L. (1990), “Computational Methods for Solving Variants of Fuerst's Model," Federal Reserve Bank of Minneapolis, working paper \#467.

Canova, F. (1998), "Detrending and Business Cycle Facts," Journal of Monetary Economics, vol. 41, no. 3 , pp. $475-512$.

Collard, F. (1999), "Spectral and Persistence Properties of Cyclical Growth," Journal of Economic Dynamics and Control, vol. 23, pp. 463-488.

Cooley, T., ed. (1995), Frontiers of Business Cycle Research, Princeton University Press.

Freeman, S., D.P. Hong and D. Peled (1999), "Endogenous Cycles and Growth with Indivisible Technological Developments," Review of Economic Dynamics, vol. 2, pp. 403-32.

Granger, C. W.J (1966), "The Typical Spectral Shape of an Economic Variable," Econometrica, vol. 34, no.1, pp. 150-161.

Grossman, G.M. and E. Helpman (1991a), "Quality Ladders in the Theory of Growth," Review of Economic Studies, vol. 63, pp. 43-61.

Grossman, G.M. and E. Helpman (1991), Innovation and Growth in the Global Economy, MIT Press.

Kydland, F.E. and E.G. Prescott (1982), “Time to Build and Aggregate Fluctuations," Econometrica, vol. 50, pp. 1345-70.

Lambson, V.E. and K.L. Phillips (1999), "Schumpeterian Growth and R\&D Ties," Mimeo, Brigham Young University.

Long, J.B. and C.I. Plosser (1983), "Real Business Cycles,” Journal of Political Economy, vol. 91, pp. 39-69.

Ozlu, E. (1996), "Aggregate Economic Fluctuations in Endogenous Growth Models," Journal of Macroeconomics, vol. 18, pp. 27-47.

Sargent, T.J. (1987), Macroeconomic Theory, second edition, Academic Press.

Schlagenhauf, D.E. and J.M. Wrase (1995), "Liquidity and Real Activity in a Simple Open Economy Model," Journal of Monetary Economics, vol. 35, pp. 431-461. 
Segerstrom, P.S., T.C.A. Anant, and E. Dinopoulos (1990), "A Schumpeterian Model of the Product Life Cycle,” American Economic Review, vol. 80, pp.1077-1091.

Solow, R.M. (1957), "Technical Change and the Aggregate Production Function," Review of Economics and Statistics, vol. 39, no. 3, pp. 312-320. 